\title{
ПРИКЛАДНОЙ АНАЛИЗ
}

DOI: $10.22363 / 2313-0660-2017-17-1-122-136$

\section{МОДЕЛИ ВЗАИМОДЕЙСТВИЯ ФОРУМА «АЗИАТСКО-ТИХООКЕАНСКОЕ ЭКОНОМИЧЕСКОЕ СОТРУДНИЧЕСТВО" (АТЭС) С МЕЖДУНАРОДНЫМИ ИНСТИТУТАМИ В ПРОЦЕССЕ ОСУЩЕСТВЛЕНИЯ МНОГОСТОРОННЕГО УПРАВЛЕНИЯ}

\author{
Е.А. Сафонкина \\ Российская академия народного хозяйства и государственной службы \\ при Президенте РФ, Москва, Российская Федерация
}

После мирового финансового кризиса 2008 г. Азиатско-Тихоокеанский регион превратился в основной драйвер глобального экономического роста, оставив далеко позади США и европейские экономики. Одним из факторов экономических успехов стали процессы региональной интеграции и упрощения условий ведения бизнеса благодаря деятельности многосторонних региональных объединений, таких как форум «Азиатско-Тихоокеанское экономическое сотрудничество» (АТЭС). В процессе регионального управления АТЭС взаимодействует с различными международными и региональными организациями, выбирая модели, позволяющие ему наилучшим образом реализовать приоритеты своей повестки дня.

В данной статье предпринята попытка выявить, какие модели взаимодействия с международными и региональными организациями наиболее характерны для АТЭС, причины и результаты обращения АТЭС к этим моделям, проследить эволюцию взаимодействия, а также оценить эффективность использования форумом международных организаций для реализации своих приоритетов. Для проведения исследования автор использовал количественный и качественный контент-анализ, а также сравнительный исторический анализ.

Автор приходит к выводу, что форум «Азиатско-Тихоокеанское экономическое сотрудничество» обладает четко сформулированной повесткой дня, направленной на реализацию изначальных задач объединения по обеспечению либерализации торговли, инвестиций и благоприятных условий ведения бизнеса в регионе. Реализуя задачи своей повестки дня, АТЭС чаще всего использует политический, финансовый и экспертный потенциал, а также инструменты и механизмы международных организаций (модель «управление через многосторонние организации). В ряде случаев АТЭС использует модель «каталитического воздействия» и «параллельного управления».

Ключевые слова: форум «Азиатско-Тихоокеанское экономическое сотрудничество» (АТЭС), международные организации, региональное управление, модели взаимодействия, эффективность, Всемирная торговая организация (ВТО), Всемирный банк, «Группа двадцати», Международный валютный фонд (МВФ)

После мирового финансового кризиса 2008 г. Азиатско-Тихоокеанский регион превратился в основной драйвер глобального экономического роста, оставив далеко позади США и европейские экономики. В 2014 г. вклад региона АТР обеспечивал почти две трети глобального экономического роста. Если в 2000 г. вклад региона в мировое производство составлял менее 30\%, то к 2014 г. этот показатель увеличился до почти $40 \%{ }^{1}$. В то время как рост реального ВВП в среднем в мире составлял не более $3,5 \%$ на протяжении последних трех лет, рост реального ВВП

${ }^{1}$ Regional Economic Outlook: Asia and Pacific. Stabilizing and Outperforming Other Regions. IMF. April 2015. URL: http://www.imf.org/external/pubs/ft/reo/2015/apd/eng/areo0415.htm (accessed: 1.08.2016). 
в странах Азии был более 5\% в указанный период². Одним из факторов экономических успехов стали процессы региональной интеграции и упрощения условий ведения бизнеса благодаря деятельности многосторонних объединений, таких как форум «Азиатско-Тихоокеанское экономическое сотрудничество» (АТЭС). В процессе регионального управления АТЭС взаимодействует с различными международными и региональными организациями, выбирая модели, позволяющие ему наилучшим образом реализовать приоритеты своей повестки дня.

Впервые модели взаимодействия институтов глобального управления с международными организациями были описаны Р. Путнамом и Н. Бейном на примере «Группы семи». Они выявили модели «каталитического воздействия», «ядра, влияющего на систему» и «параллельного управления» [Putnam, Bayne 1987: 155-157]. Применяя первую модель, многосторонний институт стимулирует или поддерживает изменения и реформирование международных организаций, например, данный подход используется «Группой двадцати» в отношении Международного валютного фонда (МВФ) (поддержка реформы квот и управления фонда). Модель «ядра, влияющего на систему» предполагает определение нового направления действий для других организаций или обеспечение политического лидерства, в котором нуждается организация. Например, «двадцатка» стимулировала процесс взаимной оценки (МАР) МВФ [Ларионова 2017]. Третья модель «параллельное управление» предполагает создание многосторонним институтом собственных механизмов, как, например, в случае создания БРИКС Нового банка развития (НБР) [Ларионова и др. 2014; Шелепов 2015; Larionova, Shelepov 2015; Ларионова 2016b].

Еще одна модель («управление через многосторонние организации») была выявлена Э. Кокотсис на примере «Группы семи/восьми» [Kokotsis 1999; Kokotsis, Daniels 1999: 75-94]. Исследователь приходит к выводу, что данная модель способствует повышению эффективности «семерки/восьмерки», «поскольку деятельность многосторонних институтов, контролируемых странами - членами «Группы семи/восьми», содействует исполнению обязательств, принятых в рамках саммитов, при условии, что эти организации являются профильными для данных специфических обязательств» [Ларионова 2016а].

Профессор Университета Торонто Джон Киртон описывает подход «управление против многосторонних институтов» в сопряжении с его моделью «союза равных» между странами - членами «Группы семи/восьми». С его точки зрения, «Группа семи/восьми» прибегает к замене старых многосторонних организаций на альтернативные, создавая новый, фундаментально отличный от традиционной системы порядок, построенный вокруг «семерки/восьмерки» (G8-centred system of its own) [Kirton 2010: 25-26; Ларионова 2016а; Kirton 2013; Киртон 2015].

Н. Бейн, также исследовавший «Группу семи/восьми», предложил еще одну модель - «управление без многосторонних институтов», поскольку, по его мнению, многосторонние институты находятся в отношениях взаимного сосуществования и отстраненности [Вауnе 2000: 45; Ларионова 2016а].

${ }^{2}$ Regional Economic Outlook: Asia And Pacific. Building on Asia's Strengths during Turbulent Times. April 2016. URL: http://www.imf.org/external/pubs/ft/reo/2016/apd/eng/areo0516.htm (accessed: 1.08.2016). 
Помимо вышеуказанных моделей, исследование дискурса «Группы семи/ восьми» позволило выявить, что «семерка» и международные организации действуют как партнеры: модель - «управление в союзе с многосторонними организациями» [Larionova 2010: 45-46; Ларионова и др. 2016].

Предполагая, что в процессе своего взаимодействия с международными организациями АТЭС использует такой набор моделей, который позволяет ему реализовать приоритеты своей повестки дня наиболее эффективным образом, автор исследовал работу форума в трех ключевых сферах: макроэкономической, сфере финансового регулирования и сфере торговли и инвестиций.

В результате анализа было определено, какие модели взаимодействия с международными организациями являются наиболее характерными для АТЭС, выявлены причины и результаты обращения АТЭС к этим моделям, эволюция взаимодействия, а также оценена эффективность использования форумом международных организаций для реализации своих приоритетов и меняющейся повестки дня.

\section{МЕТОДОЛОГИЯ}

Благодаря контент-анализу официальных документов АТЭС было проведено качественное и количественное исследование упоминаний международных организаций. Для контент-анализа использовалась специальная база данных, включающая документы АТЭС, принятые на саммитах лидеров, встречах министров торговли, финансов, энергетики и других треков с 2008 по 2016 г. База данных позволяет проанализировать данные по абсолютному количеству упоминаний в документах, относительные данные по доле конкретного института в общем количестве упоминаний. Также применяется относительный показатель интенсивности упоминаний, позволяющий сопоставить взаимодействие АТЭС с международными организациями с учетом различия в объеме документов, принятых в рамках разных саммитов. Показатель интенсивности рассчитывается по формуле:

$$
\mathrm{Di}=\mathrm{Mi} / \mathrm{Si}
$$

где $D i-$ интенсивность упоминаний института за определенный период, $M i-$ количество упоминаний данного института в документах АТЭС, принятых за период, $\mathrm{Si}$ - общее количество текстовых символов в документах за данный период. Для большей наглядности результатов $D i$ умножается на 10000 [Шелепов 2015].

С целью выявления моделей взаимодействия АТЭС с международными институтами был проведен качественный контент-анализ документов АТЭС.

\section{СТАТИСТИКА УПОМИНАНИЙ МЕЖДУНАРОДНЫХ ИНСТИТУТОВ В ДОКУМЕНТАХ АТЭС}

Из всего массива международных организаций, упоминания которых встречаются в официальных документах АТЭС, топ-10 составляют Всемирная торговая организация (ВТО), Всемирный банк, «Группа двадцати», Организация экономического сотрудничества и развития (ОЭСР), собственный институт АТЭС - Образовательная сеть (Education Network), Организация Объединенных Наций (OOH), Азиатский банк развития (АБР), Ассоциация государств Юго-Восточной Азии (АСЕАН), Продовольственная и сельскохозяйственная организация ООН (ФАО) и Международный валютный фонд (МВФ). Частые упоминания данных орга- 
низаций можно объяснить тем, что все они работают в сферах, являющихся ключевыми для АТЭС: торговли, финансов, образования, продовольственной безопасности.

Интенсивность и число упоминаний международных организаций в совокупности достаточно равномерны, однако в последние годы наблюдается их незначительное снижение (рис. 1; табл. 1). Это связано в том числе с тем, что за последнее десятилетие структура АТЭС значительно расширилась за счет создания многочисленных собственных механизмов, реализующих мандаты повестки дня АТЭС, т.е. потребность в отсылке на опыт и экспертизу международных организаций в документах лидеров снизилась ${ }^{3}$.

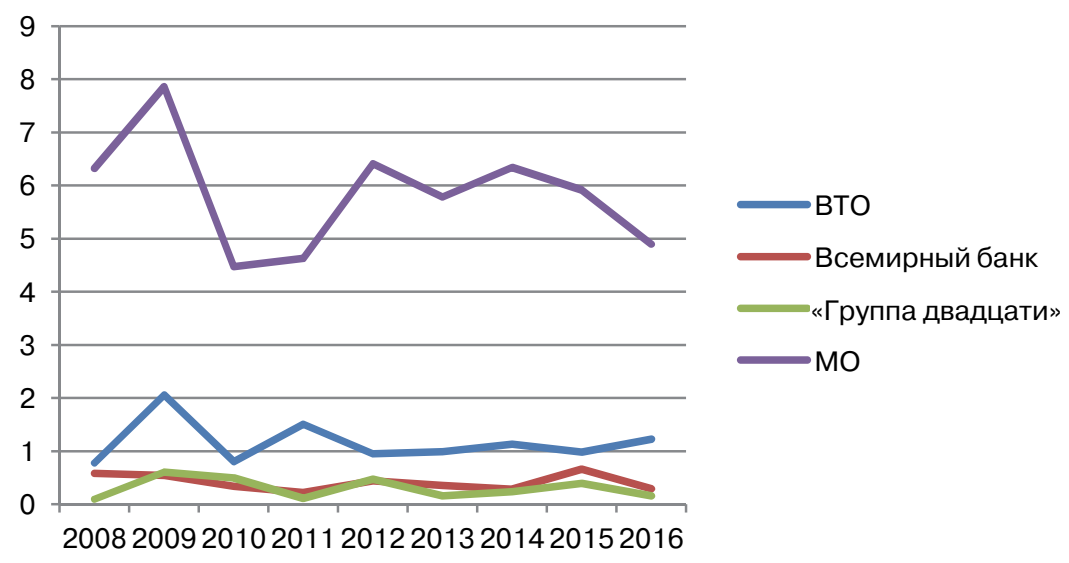

Рис. 1. Интенсивность упоминаний международных институтов, ВТО, Всемирного банка и «Группы двадцати» в документах АТЭС (2008-2016 гг.) / The intensity of the references to international institutions, the WTO, World Bank and G20 in APEC documents

Источник: Расчеты автора

Число упоминаний международных организаций в документах АТЭС The number of references to international organizations in APEC documents

\begin{tabular}{|c|c|c|c|}
\hline $\begin{array}{l}\text { Год / } \\
\text { Year }\end{array}$ & $\begin{array}{c}\text { Число символов в документах / } \\
\text { Number of symbols } \\
\text { in the documents }\end{array}$ & $\begin{array}{c}\text { Всего упоминаний МО / } \\
\text { Total number of references } \\
\text { to international organiza- } \\
\text { tions }\end{array}$ & $\begin{array}{l}\text { Интенсивность упоминаний } \\
\text { MO / The intensity of the of } \\
\text { references to international } \\
\text { organizations }\end{array}$ \\
\hline 2008 & 205547 & 130 & 6,32 \\
\hline 2009 & 165387 & 130 & 7,86 \\
\hline 2010 & 261453 & 117 & 4,47 \\
\hline 2011 & 179360 & 83 & 4,63 \\
\hline 2012 & 294960 & 189 & 6,40 \\
\hline 2013 & 252629 & 146 & 5,78 \\
\hline 2014 & 424159 & 269 & 6,34 \\
\hline 2015 & 377037 & 223 & 5,91 \\
\hline \multirow[t]{2}{*}{2016} & 310357 & 152 & 4,90 \\
\hline & $\begin{array}{c}\text { Общее число символов / } \\
\text { The total number of symbols: } \\
2470889\end{array}$ & $\begin{array}{c}\text { Общее число упоминаний / } \\
\text { The total number } \\
\text { of references: } 1439\end{array}$ & \\
\hline
\end{tabular}

Источник: Расчеты автора

3 По состоянию на декабрь 2016 г. структура АТЭС включает 4 ключевых комитета, 15 рабочих групп и свыше 10 иных форматов. URL: http://www.apec.org. 
Лидером по числу упоминаний в документах АТЭС является ВТО. Наблюдается значительный разрыв между общим числом упоминаний ВТО (274) и Всемирного банка, занимающего второе место в топ-10 по количеству упоминаний (102). Это обусловлено тем, что с момента создания одной из ключевых задач АТЭС является либерализация и упрощение торговли в регионе.

Наибольшая интенсивность упоминаний ВТО в документах АТЭС отмечается в 2009 г., что объясняется очередной задержкой завершения Дохийского раунда торговых переговоров ${ }^{4}$.

В 2016 г. наблюдается небольшое повышение интенсивности упоминаний ВТО по сравнению с предыдущими председательствами. Это связано с выработкой Соглашения ВТО об упрощении условий торговли (WTO Trade Facilitation Agreement (TFA)) и процессом его ратификации странами - членами ВТО. Соглашение находится в русле одного из ключевых приоритетов АТЭС по продвижению свободной торговли, поэтому лидеры АТЭС призвали экономики форума и другие страны ВТО ратифицировать соглашение как можно скорее 5

Следующим по числу упоминаний институтом в документах АТЭС является Всемирный банк. Как видно на рис. 1, наибольшая интенсивность упоминаний наблюдается в 2015 г. В этом году министры финансов экономик - участниц АТЭС поручили Всемирному банку провести исследование и подготовить доклад о возможных механизмах финансирования борьбы с рисками природных бедствий, включая покрытие рисков ${ }^{6}$.

На третьем месте по числу упоминаний в официальных документах АТЭС находится «Группа двадцати».

Как можно видеть на рис. 1, наибольшая интенсивность упоминаний «двадцатки» наблюдалась в 2009, 2012 и 2015 гг. со значительным снижением в 2011, 2013 и 2016 гг. Применительно к 2009 г. подобная тенденция объясняется повышенным вниманием и интересом к недавно созданному институту, а также соответствием обязательств «двадцатки» по обеспечению уверенного, устойчивого и сбалансированного глобального экономического роста приоритетам АТЭС 7 . В 2012 г. мексиканское председательство в «Группе двадцати» включило в повестку вопросы борьбы с природными бедствиями и их последствиями, что является важной темой для АТЭС. Рост числа упоминаний «двадцатки» в 2015 г. обусловлен тем, что экономики АТЭС поддержали новые инструменты, используемые G20, в том числе проект BEPS, в силу их соответствия приоритетам повестки дня АТЭС.

${ }^{4}$ Meeting of APEC ministers responsible for trade. Singapore, 21-22 July, 2009. Statement of the Chair. URL: http://www.mofa.go.jp/policy/economy/apec/2009/mrt0907-1.pdf (accessed: 4.08.2016).

52016 Leaders' Declaration. Lima, Peru 20 November 2016. URL: http://www.apec.org/ Meeting-Papers/Leaders-Declarations/2016/2016_aelm.aspx (accessed: 2.12.2016).

${ }_{6} 2015$ APEC Finance Ministerial Meeting. Cebu, Philippines 11 September 2015. URL: http://www.apec.org/Meeting-Papers/Sectoral-Ministerial-Meetings/Finance/2015_finance.aspx (accessed: 1.08.2016).

72009 Leaders' Declaration. Singapore 14 November 2009. URL: http://www.apec.org/MeetingPapers/Leaders-Declarations/2009/2009_aelm.aspx (accessed: 3.08.2016). 
Подводя итог, можно говорить о том, что максимальная интенсивность того или иного института в документах АТЭС наблюдается тогда, когда этим институтом вырабатываются и реализуются меры, которые поддерживает АТЭС в рамках своей повестки дня.

\section{ОСОБЕННОСТИ ВЗАИМОДЕЙСТВИЯ АТЭС С КЛЮЧЕВЫМИ ИНСТИТУТАМИ}

В данном разделе статьи будут рассмотрены особенности взаимодействия АТЭС с ключевыми институтами по следующим сферам: макроэкономика, финансы и торговля, и инвестиции. Подобный подход позволяет определить приоритеты АТЭС в указанных сферах и, соответственно, выбор моделей взаимодействия с международными организациями.

\section{Макроэкономика}

Ключевыми направлениями макроэкономической политики АТЭС являются обеспечение экономического роста, макроэкономической стабильности, включая борьбу с инфляцией, реализация структурных реформ, обеспечение занятости населения и многие другие. Основными партнерами АТЭС в рамках данного блока сотрудничества являются Всемирный банк, Азиатский банк развития и «Группа двадцати».

\section{Всемирный банк}

Для АТЭС характерны следующие модели взаимодействия с Всемирным банком:

- привлечение данной организации в качестве партнера к реализации инициатив АТЭС (модель «управление через многосторонние организации»);

- использование экспертизы и инструментов Всемирного банка для выработки своих собственных инструментов (модель «управление через многосторонние организации»);

- передача поручений о подготовке специализированных исследований по приоритетным направлениям работы АТЭС (модель «управление через многосторонние организации»).

Одним из ярких примеров модели «управление через многосторонние организации» в отношениях АТЭС и Всемирного банка является Глобальный фонд продовольственной безопасности, учрежденный в ноябре 2011 г. в формате государственно-частного партнерства под управлением Всемирного банка. Фонд призван содействовать усилиям АТЭС в сфере повышения уровня продовольственной безопасности, в том числе за счет программ подготовки специалистов, которые разрабатываются при помощи Всемирного банка ${ }^{8}$. Также в качестве примера можно привести поручение Всемирному банку в 2015 г. со стороны министров финан-

${ }^{8}$ Creation of Global Food Safety Partnership. URL: http://www.state.gov/r/pa/prs/ps/2011/11/ 177059.htm (accessed: 7.08.2016). 
сов АТЭС провести исследование и подготовить доклад о возможных региональных механизмах финансирования борьбы с природными бедствиями'.

АТЭС активно использует экспертизу Всемирного банка в следующих сферах:

- глобальные цепочки добавленной стоимости;

— конкурентоспособность услуг (например, разработка долгосрочной стратегической дорожной карты по обеспечению конкурентоспособности услуг (АРЕС Services Competitiveness Roadmap $)^{10}$;

- государственно-частные партнерства (например, выработка совместных стандартов ГЧП) ${ }^{11}$;

- структурные реформы ${ }^{12}$.

Таким образом, АТЭС взаимодействует с Всемирным банком, преимущественно используя экспертный и политический потенциал данного института для реализации собственной повестки дня (модель «управление через многосторонние организации»), что обеспечивает повышение эффективности работы АТЭС. В отношении Всемирного банка АТЭС не применяет модель «каталитического воздействия», поскольку в официальных документах АТЭС не содержится призывов к реформированию данного института.

\section{Азиатский банк развития (АБР)}

Азиатский банк развития помогает странам Азиатско-Тихоокеанского региона развивать торговлю друг с другом посредством совершенствования механизмов обмена информацией и реформирования таможенных органов. Партнерство АТЭС и АБР насчитывает почти 20 лет.

Для АТЭС характерны следующие модели взаимодействия с АБР:

- привлечение данной организации в качестве партнера к реализации инициатив АТЭС (модель «управление через многосторонние организации»);

- использование экспертизы и инструментов АБР для выработки своих собственных инструментов (модель «управление через многосторонние организации»);

- передача поручений о подготовке специализированных исследований по приоритетным направлениям работы АТЭС (модель «управление через многосторонние организации»).

АБР является секретариатом для инициативы АТЭС по подготовке финансовых регуляторов.

92015 APEC Finance Ministerial Meeting. Cebu, Philippines 11 September 2015. URL: http://www.apec.org/Meeting-Papers/Sectoral-Ministerial-Meetings/Finance/2015_finance.aspx (accessed: 1.08.2016).

102016 Meeting of APEC Ministers Responsible for Trade. Arequipa, Peru 18 May 2016. URL: http://www.apec.org/Meeting-Papers/Sectoral-Ministerial-Meetings/Trade/2016_trade.aspx (accessed: 3.08.2016).

112016 APEC Finance Ministerial Meeting. Lima, Peru 15 October 2016. URL: http://www.apec.org/ Meeting-Papers/Sectoral-Ministerial-Meetings/Finance/2016_finance.aspx (accessed: 13.11.2016).

12 APEC Structural Reform Ministerial Meeting. Cébu, Philippines. Statement. URL: http://www.apec.org/ /media/Files/MinisterialStatements/Structural\%20Reform/PCM_Press\% 20Conference\%20Material.pdf (accessed: 7.08.2016). 
АТЭС использует экспертизу АБР в сферах исследования и мониторинга инвестиционной политики в регионе; реализации инфраструктурных проектов с долей финансирования со стороны частного сектора; борьбы с отмыванием денежных средств и финансированием терроризма ${ }^{13}$.

Таким образом, как и в случае с Всемирным банком, АТЭС преимущественно использует экспертный и финансовый потенциал АБР в блоках работ своей повестки дня (модель «управление через многосторонние организации»).

\section{«Группа двадцати»}

Девять экономик АТЭС являются членами «Группы двадцати» (Австралия, Индонезия, Канада, Китай, Мексика, Республика Корея, Россия, США, Япония) ${ }^{14}$. В силу того что перед странами - участницами обоих институтов стоят схожие задачи, однако «двадцатка» в силу своего глобального лидерства обладает большими возможностями выработки мер для коллективной реализации, для АТЭС характерна поддержка и использование инструментов «двадцатки», способных помочь решению стоящих перед экономиками АТЭС проблем (модель «управление через многосторонние организации»).

АТЭС внимательно отслеживает нововведения «двадцатки», поскольку в большинстве случаев новые инструменты «Группы двадцати» упоминаются в документах АТЭС в тот же год, когда об их запуске было официально объявлено самой «двадцаткой».

В документах АТЭС «двадцатка» упоминается с момента своего становления в 2008 г., преимущественно в декларациях лидеров АТЭС, документах финансового и торгового треков.

Ключевыми инструментами «двадцатки», поддержанными АТЭС являются:

- рамочное соглашение по обеспечению уверенного, устойчивого и сбалансированного роста ${ }^{15,16}$;

- рекомендации Базельского комитета по банковскому надзору ${ }^{17}$;

- принципы высокого уровня ОЭСР / Международной сети по финансовому образованию (INFE) в сфере национальных стратегий для финансового образования ${ }^{18}$;

— принципы высокого уровня ОЭСР/G20 по обеспечению финансирования долгосрочных инвестиций со стороны институциональных инвесторов ${ }^{19}$;

13 APEC and the Asian Development Bank: 12 Things to Know. URL: http://www.adb.org/news/ features/apec-and-asian-development-bank-12-things-know (accessed: 4.08.2016).

${ }_{14}$ APEC Member Economies. URL: http://www.apec.org/about-us/about-apec/membereconomies.aspx; G20 Members. URL: http://g20.org.tr/about-g20/g20-members (accessed: 3.08.2016).

152009 Leaders' Declaration. Singapore 14 November 2009. URL: http://www.apec.org/MeetingPapers/Leaders-Declarations/2009/2009_aelm.aspx (accessed: 3.08.2016).

16 16th APEC FINANCE MINISTERS' 'MEETING. JOINT MINISTERIAL STATEMENT. URL: http://www.mof.go.jp/english/international_policy/convention/apec/20091112.pdf (accessed: 4.08.2016).

17 18th APEC Finance Ministers' Meeting Joint Ministerial Statement. URL: http://www.mof.go.jp/ english/international_policy/convention/apec/20111110.pdf (accessed: 4.08.2016).

18 19th APEC Finance Ministers' Meeting Joint Ministerial Statement (Moscow, Russia, August 30, 2012). URL: http://www.mof.go.jp/english/international_policy/convention/apec/20120830.htm (accessed: 4.08.2016). 
— план действий G20/OЭСР по размыванию налогооблагаемой базы и перемещению прибыли (план BEPS) ${ }^{20,21}$;

— принципы высокого уровня G20/ОЭСР по финансированию $\mathrm{MCП}^{22}$.

Другими направлениями работы «двадцатки», подходы в рамках которых поддерживает АТЭС, являются рационализация и отказ от неэффективных субсидий на ископаемое топливо; борьба с изменением климата; финансирование борьбы с рисками природных катастроф; развитие глобальных цепочек добавленной стоимости.

Таким образом, АТЭС удалось выстроить достаточно эффективную систему взаимодействия с «Группой двадцати», с одной стороны, поддерживая ее инициативы, с другой - используя опыт и механизмы данного института глобального управления для реализации своих собственных задач.

\section{Финансовое регулирование}

Работа АТЭС в сфере финансового регулирования ведется в рамках трека министров финансов (FMP). Основными партнерами АТЭС в рамках данного министерского трека являются МВФ, Всемирный банк, Азиатский банк развития, Межамериканский банк развития, ОЭСР и Деловой консультативный совет (ДКС) АТЭС, руководители которых участвуют во встречах министров финансов ${ }^{23}$.

\section{Международный валютный фонд (МВФ)}

МВФ является важным партнером АТЭС по направлению работы финансового трека с учетом многолетней и всеохватывающей экспертизы фонда. Директорраспорядитель МВФ на постоянной основе участвует в саммитах лидеров АТЭС ${ }^{24}$, а высокопоставленные представители фонда — во встречах министров финансов форума. В рамках перуанского председательства лидеры АТЭС впервые провели специальную встречу по вопросу деятельности МВФ в регионе ${ }^{25}$.

192013 Meeting of APEC Ministers Responsible for Trade. URL: http://www.international.gc.ca/ apec/apec_2013_statement_a.aspx?lang=eng (accessed: 4.08.2016).

2021 st APEC Finance Ministers' Meeting Joint Ministerial Statement (Beijing, China, 22 October 2014). URL: http://www.mof.go.jp/english/international_policy/convention/apec/20141021.htm (accessed: 4.08.2016).

212016 APEC Finance Ministerial Meeting, Lima, Peru 15 October 2016. URL: http://www.apec.org/ Meeting-Papers/Sectoral-Ministerial-Meetings/Finance/2016_finance.aspx (accessed: 13.11.2016).

${ }^{22} 2015$ APEC Finance Ministerial Meeting. Cebu, Philippines 11 September 2015. URL: http://www.apec.org/Meeting-Papers/Sectoral-Ministerial-Meetings/Finance/2015_finance.aspx (accessed: 1.08.2016).

${ }^{23}$ APEC Finance Ministers' Process. URL: https://aric.adb.org/initiative/apec-finance-ministersprocess (accessed: 1.08.2016).

${ }^{24}$ Например: The Business Case for Women's Empowerment by Christine Lagarde, IMF Managing Director, APEC CEO Summit, Peru, November 18, 2016. URL: http://www.imf.org/en/news/ articles/2016/11/18/sp111816-the-business-case-for-womens-empowerment; Press Release: Statement by IMF Managing Director Christine Lagarde at the APEC Leaders Summit. URL: http://www.imf.org/ en/news/articles/2015/09/14/01/49/pr12308 (accessed: 2.12.2016).

${ }_{25}$ Встреча лидеров экономик форума АТЭС по вопросу деятельности МВФ в регионе. URL: http://kremlin.ru/events/president/news/53282 (дата обращения: 2.12.2016). 
Во взаимодействии с МВФ АТЭС преимущественно использует две модели: модель «каталитического воздействия» и модель «управление через многосторонние организации».

В силу того что среди членов АТЭС есть крупные развивающиеся экономики, такие как Китай, Индонезия, Мексика, АТЭС неоднократно высказывался в поддержку реализации реформы квот и управления $\mathrm{MB} \Phi^{26}$, что демонстрирует модель «каталитического воздействия».

Примерами использования модели «управление через многосторонние организации», например, является просьба министров финансов АТЭС к МВФ совместно с Всемирным банком, Международной финансовой корпорацией (IFC) и Азиатским банком развития подготовить доклад о потоках портфельных инвестиций в регионе ${ }^{27}$.

\section{Собственные институты АТЭС}

Собственные институты АТЭС демонстрируют собой модель «параллельного управления» в отношении имеющихся глобальных финансовых институтов. Таким институтом является Азиатско-Тихоокеанский финансовый форум (Asia-Pacific Financial Forum (APFF)), созданный в 2013 г. в качестве платформы для взаимодействия институтов, экспертных и иных организаций в целях развития и укрепления финансовых рынков в Азиатско-Тихоокеанском регионе ${ }^{28}$. При создании собственного института и определении его миссии АТЭС применяет модель «ядра, влияющего на систему», а в дальнейшем - модель «управление через многосторонние организации».

\section{Торговля и инвестиции}

Исторически сложившаяся миссия АТЭС направлена на либерализацию и упрощение торговли в регионе ${ }^{29}$. ВТО является ключевой международной организацией, с которой АТЭС взаимодействует по своей торговой повестке дня.

\section{BTO}

Как было показано в предыдущем разделе, ВТО является наиболее часто встречающимся институтом в документах АТЭС в силу важности торговых вопросов в повестке дня института.

Все экономики - участницы АТЭС являются членами $\mathrm{BTO}^{30}$, последней к ВТО присоединилась Россия (в 2012 г.), причем АТЭС в своих официальных документах неоднократно поддерживал процесс присоединения России к ВТО.

262006 Leaders' Declaration. Ha Noi, Viet Nam 18 November 2006. URL: http://www.apec.org/ Meeting-Papers/Leaders-Declarations/2006/2006 aelm.aspx (accessed: 7.08.2016).

${ }^{27}$ First APEC Finance Ministers Meeting (Honolulu, Hawaii, Mar 18-19, 1994) JOINT MINISTERIAL STATEMENT. URL: http://www.apec.org/ /media/Files/MinisterialStatements/Finance/ 94_fmm_jms.pdf (accessed: 7.08.2016).

${ }_{28}$ ABOUT THE 2014 ASIA-PACIFIC FINANCIAL FORUM. URL: http://www.ncapec.org/ events/APFF/ (accessed: 13.11.2016).

${ }^{29}$ Committee on Trade and Investment. URL: http://www.apec.org/Home/Groups/Committeeon-Trade-and-Investment (accessed: 7.08.2016). 
Ежегодно лидеры АТЭС в своих декларациях подтверждают «центральную роль и примат многосторонней торговой системы под эгидой ВТО» ${ }^{31}$, а начиная с 2010 г. принимают отдельное заявление в поддержку многосторонней торговой системы и Министерской конференции ВТО.

В своей работе по формированию концепции Азиатско-Тихоокеанской зоны свободной торговли (АТЗСТ) экономики АТЭС изначально подчеркивали, что АТЗСТ должна соответствовать правилам и нормам $\mathrm{BTO}^{32}$.

В отношении ВТО АТЭС чаще всего использует модель «каталитического воздействия» и «управления через многосторонние организации», призывая экономики-участницы к имплементации соглашений ВТО. Модель «каталитического воздействия» наиболее явно прослеживается в отношении Дохийского раунда переговоров $\mathrm{BTO}^{33}$.

Среди поддержанных АТЭС инициатив ВТО:

- начало переговоров о существенном расширении спектра товаров, подпадающих под Соглашение ВТО по информационным технологиям (2011 г.);

— начало переговоров по расширению охвата Соглашения ВТО об информационных технологиях (2014 г.);

— начало переговоров по Соглашению ВТО об экологических товарах (2014 г.);

- проект по созданию базы данных о торговле товарами и услугами с добавленной стоимостью в рамках ГСЦ (TiVA) (2014 г.);

- Соглашение об упрощении условий торговли ВТО (TFA) $(2015 \text { г.) })^{34,35}$.

Таким образом, АТЭС использует инструменты ВТО для достижения своих целей по либерализации торговли в регионе, тем самым способствуя повышению легитимности организации среди экономик-участниц.

По итогам проведенного исследования автор приходит к выводу, что форум «Азиатско-Тихоокеанское экономическое сотрудничество» (АТЭС) в ходе реализации функций регионального управления взаимодействует с широким кругом

30 Understanding The WTO: The Organization. Members and Observers. URL: https://www.wto.org/ english/thewto_e/whatis_e/tif_e/org6_e.htm; APEC Member Economies. URL: http://www.apec.org/ about-us/about-apec/member-economies.aspx (accessed: 3.08.2016).

31 Декларация по итогам встречи лидеров экономик - участниц форума ATЭC. URL: http://economy.gov.ru/minec/press/news/2015191107 (дата обращения: 1.08.2016).

322008 APEC Ministerial Meeting. Lima, Peru 19 November 2008. URL: http://www.apec.org/ Meeting-Papers/Annual-Ministerial-Meetings/Annual/2008/2008_amm.aspx (accessed: 3.08.2016).

33 Декларация по итогам 22-й встречи лидеров экономик - участниц форума АТЭС, Пекин, Китай 11 ноября 2014 года. Пекинская повестка дня интеграции, инновационного развития и взаимосвязанности в Азиатско-Тихоокеанском регионе. URL: http://www.mid.ru/foreign_policy/ rso/-/asset_publisher/0vP3hQoCPRg5/content/id/940165 (дата обращения: 3.08.2016).

342016 Meeting of APEC Ministers Responsible for Trade. Arequipa, Peru 18 May 2016. URL: http://www.apec.org/Meeting-Papers/Sectoral-Ministerial-Meetings/Trade/2016_trade.aspx (accessed: 3.08.2016).

35 По состоянию на декабрь 2016 года, почти все экономики - участницы АТЭС ратифицировали TFA, за исключением Индонезии и Папуа - Новой Гвинеи. Источник: Trade facilitation news archive. URL: https://www.wto.org/english/news_e/archive_e/fac_arc_e.htm (accessed: 3.08.2016). 
международных, региональных и секторальных организаций. При этом АТЭС выбирает модели взаимодействия, позволяющие ему решить свои задачи и повысить эффективность своей работы.

Как показывают данные исследования, чаще всего АТЭС использует политический, финансовый и экспертный потенциал, а также инструменты и механизмы международных организаций (модель «управление через многосторонние организации»), тем самым реализуя задачи своей собственной повестки дня, а с другой стороны - способствуя повышению легитимности данных международных организаций в глобальном пространстве. Одним из ярких примеров такого взаимодействия является проект по созданию Глобального фонда продовольственной безопасности, который был учрежден в ноябре 2011 г. в формате государственночастного партнерства под управлением Всемирного банка в соответствии с меморандумом о взаимопонимании между Форумом сотрудничества в области продовольственной безопасности АТЭС (Food Safety Cooperation Forum (FSCF) - подгруппой Комитета по торговле и инвестициям АТЭС (СТI) и ВБ. Ключевые направления деятельности фонда включают разработку, тестирование и оценку программ подготовки специалистов в области продовольственной безопасности; и укрепление систем анализа систем по обеспечению продовольственной безопасности в экономиках АТЭС. Также в качестве примера можно привести поручение Всемирному банку в 2015 г. со стороны министров финансов АТЭС провести исследование и подготовить доклад о возможных региональных механизмах финансирования борьбы с природными бедствиями.

Модель «каталитического воздействия» встречается достаточно редко, преимущественно в отношении МВФ и ВТО. В силу того что среди членов АТЭС есть крупные развивающиеся экономики, такие как Китай, Индонезия, Мексика, АТЭС неоднократно высказывался в поддержку реализации реформы квот и управления МВФ. В силу того что с момента создания одной из ключевых задач АТЭС является либерализация и упрощение торговли в регионе, лидеры экономик - участниц АТЭС ежегодно в своих декларациях призывают к завершению Дохийского раунда переговоров ВТО. Например, в 2014 г. они обязались «энергично и творчески играть роль лидера в совместном со всеми членами ВТО поиске путей выхода из этого тупика и реализации балийских решений, продолжив работу над постбалийской программой действий, которая должна стать краеугольным камнем для завершения Дохийского раунда» ${ }^{36}$.

Нежелание / невозможность использования существующих структур для решения задач АТЭС определяет потребность создания собственных структур (модель «параллельного управления»). Таким институтом, например, является Азиатско-Тихоокеанский финансовый форум (Asia-Pacific Financial Forum (APFF), созданный в 2013 г. в качестве платформы для взаимодействия институтов, экспертных и иных организаций в целях развития и укрепления финансовых рынков в Азиатско-Тихоокеанском регионе. Фактически в отношении собственных структур АТЭС использует модель «ядра, влияющего на систему», определяя их миссию и направление работ.

36 Декларация по итогам 22-й встречи лидеров экономик-участниц форума АТЭС Пекин, Китай 11 ноября 2014 года. URL: http://www.mid.ru/forum-aziatsko-tihookeanskoe-ekonomiceskoesotrudnicestvo-ates-/-/asset_publisher/0vP3hQoCPRg5/content/id/940165 (accessed: 1.08.2016). 
Благодарность: Исследование выполнено при финансовой поддержке РГНФ в рамках проекта проведения научных исследований (Модели взаимодействия международных институтов в процессе осуществления многостороннего управления в сферах макроэкономической политики, финансового регулирования, международной торговли и инвестиций), проект № 15-07-00022.

\section{БИБЛИОГРАФИЧЕСКИЙ СПИСОК}

Киртон Д.Д. Анализ причин успешности саммитов БРИКС // Вестник международных организаций: образование, наука, новая экономика. 2015. Т. 10 (2). С. 9-38. DOI: 10.17323/1996-7845-2015-02-09.

Ларионова М.В. «Группа двадцати» и международные организации: взаимодействие для обеспечения сильного, устойчивого и сбалансированного роста // Вестник международных организаций: образование, наука, новая экономика. 2017. Т. 12 (2) (в печати).

Ларионова М.B. Оценка эффективности взаимодействия международных институтов в процессе глобального управления // Вестник международных организаций: образование, наука, новая экономика. 2016а. T. 11 (1). C. 126-152. DOI: 10.17323/1996-7845/2016-01-126.

Ларионова М.B. Российское председательство в БРИКС: модели взаимодействия с международными институтами // Вестник международных организаций: образование, наука, новая экономика. 2016b. T. 11 (2). C. 113-139. DOI: 10.17323/1996-7845-2016-02-113.

Ларионова М.В., Рахмангулов М.Р., Сахаров А.Г., Шелепов А.В. Формирование повестки дня БРИКС в сфере здравоохранения // Вестник международных организаций: образование, наука, новая экономика. 2014. Т. 9 (4). С. 102-125.

Ларионова М.В., Рахмангулов М.Р., Шелепов А.В. Что влияет на исполнение обязательств «Группы двадцати» и БРИКС: сравнительный анализ // Вестник международных организаций: образование, наука, новая экономика. 2016. Т. 11 (3). С. 99-131. DOI: 10.17323/1996-7845-2016-03-99.

Шелепов A.B. БРИКС и международные институты: модели взаимодействия в процессе осуществления многостороннего управления // Вестник международных организаций: образование, наука, новая экономика. 2015. T. 10 (4). С. 7-28. DOI: 10.17323/1996-7845-2015-04-07.

Bayne N. Hanging in There: The G7 and G8 Summit in Maturity and Renewal. Aldershot: Ashgate; 2000.

Kirton J. G20 Governance for a Globalized World. Farnham: Ashgate; 2013.

Kirton J. Multilateral Organizations and G8 Governance: A Framework for Analysis. In: Kirton J., Larionova M., Savona P. editors. Making Global Governance Effective: Hard and Soft Law Institutions in a Crowded World. Farnham: Ashgate; 2010. P. $23-42$.

Kokotsis E. Keeping International Commitments: Compliance, Credibility and the G7, 1988-1995. New York: Garland Publishing; 1999.

Kokotsis E., Daniels J. G8 Summits and Compliance. In: Hodges M., Daniels J. and Kirton J. editors. The G8's Role in the New Millennium. Aldershot: Ashgate; 1999. p. 75—94.

Larionova $M$. The New Partnership between Multilateral Organizations and the G8. In: Kirton J., Larionova M., Savona P. editors. Making Global Governance Effective: Hard and Soft Law Institutions in a Crowded World. Farnham: Ashgate; 2010. p. 43-62.

Larionova M., Shelepov A. Is BRICS Institutionalization Enhancing its Effectiveness. In: Rewizorski M. editor. The European Union and the BRICS: Complex Relations in the Era of Global Governance. Springer; 2015. p. 39-55.

Putnam R., Bayne N. Hanging Together. Cooperation and Conflict in the Seven-Power Summits. London: Sage Publications; 1987.

Дата поступления статьи: 04.02.2017

Для цитирования: Сафонкина E.A. Модели взаимодействия форума «Азиатско-Тихоокеанское экономическое сотрудничество» (АТЭС) с международными институтами в процессе осуществления многостороннего управления // Вестник Российского университета дружбы народов. Серия: Международные отношения. 2017. Т.17. № 1. С. $122-136$. 
Сведения об авторе: Сафонкина Елизавета Андреевна - научный сотрудник Центра исследований международных институтов (ЦИМИ), Российская академия народного хозяйства и государственной службы при Президенте РФ (РАНХиГС) (e-mail: safonkina-ea@ranepa.ru).

DOI: $10.22363 / 2313-0660-2017-17-1-122-136$

\title{
ASIA-PACIFIC ECONOMIC COOPERATION (APEC): MODELS OF ENGAGEMENT WITH INTERNATIONAL INSTITUTIONS IN THE PROCESS OF REGIONAL GOVERNANCE
}

\author{
E.A. Safonkina \\ Russian Presidential Academy of National Economy \\ and Public Administration (RANEPA), Moscow, Russia
}

\begin{abstract}
After the global financial crisis in 2008 the Asia-Pacific region has become a main driver of global economic growth leaving behind the US and European economies. The regional integration processes and business environment improvement as a result of the multilateral regional fora's activities, such as the Asia-Pacific Economic Cooperation (APEC) laid the foundation for such economic successes. In the process of regional governance the APEC engages with various international and regional organizations applying the models which help it to address its agenda demands in the best way.

The article aims to explore what models of engagement with international and regional organizations the APEC forum applies in the process of regional governance; reasons and results of applying these models; track the evolution of engagement as well as assess the effectiveness of APEC's engagement with international organizations in the context of shifting agenda. The research methods the author applied include qualitative and quantitative content analysis and comparative historical analysis. The official APEC documents adopted at the summits and ministerial meetings constituted the evidence base for the analysis.

The author comes to the conclusion that the Asia-Pacific Economic Cooperation has clearly organized agenda aimed at implementing primary goals on trade and investment liberalization and favorable business environment in the region. Accomplishing objectives of its agenda the APEC takes advantage of policy, finance and expert potential as well as instruments and mechanisms of the international organizations (model "governance through multilateral organizations"). The model of "catalytic influence" is applied by the APEC in very rare cases. APEC applies the model of "parallel treatment" when it establishes its own bodies. APEC uses the "core group" model when it defines the mission of its own bodies as well as gives mandates to the international institutions.

Drawing the results of the study it could be said that the APEC has formed a flexible and effective system of engagement with third-party organizations which helps it to make headway in implementing its objectives.
\end{abstract}

Key words: Asia-Pacific Economic Cooperation (APEC), international organizations, regional governance, models of engagement, effectiveness, World Trade Organization (WTO), World Bank, G20, International Monetary Fund (IMF)

Acknowledgements: The research was carried out with financial support of Russian Humanities Research Foundation within the framework of a research project "Models of international institutions engagement in the process of multilateral governance in the areas of macroeconomic policy, financial regulation, international trade, investment and infrastructure”, project № 15-07-00022.

\section{REFERENCES}

Bayne, N. (2000). Hanging in There: The G7 and G8 Summit in Maturity and Renewal. Aldershot: Ashgate.

Kirton, J. (2013). G20 Governance for a Globalized World. Farnham: Ashgate. 
Kirton, J. (2010). Multilateral Organizations and G8 Governance: A Framework for Analysis. In: Kirton J., Larionova M., Savona P. editors. Making Global Governance Effective: Hard and Soft Law Institutions in a Crowded World. Farnham: Ashgate. p. $23-42$.

Kirton, J. J. (2015). Explaining the BRICS Summit Solid, Strengthening Success. International Organisations Research Journal (IORJ), 10 (2), 9-38. DOI: 10.17323/1996-7845-2015-02-09. (In Russ.).

Kokotsis, E. (1999). Keeping International Commitments: Compliance, Credibility and the G7, 19881995. New York: Garland Publishing.

Kokotsis, E., \& Daniels, J. (1999). G8 Summits and Compliance. In: Hodges M., Daniels J. and Kirton J. editors. The G8's Role in the New Millennium. Aldershot: Ashgate. p. 75-91.

Larionova, M. (2010). The New Partnership between Multilateral Organizations and the G8. In: Kirton J., Larionova M., Savona P. editors. Making Global Governance Effective: Hard and Soft Law Institutions in a Crowded World. Farnham: Ashgate. p. 43-62.

Larionova, M. V. (2016a). Assessing Summit Engagement with Other International Organizations in Global Governance. International Organisations Research Journal (IORJ), 11 (1), 126-152. DOI: 10.17323/1996-7845/2016-01-126. (In Russ.).

Larionova, M. V. (2016b). Russia's 2015 BRICS Presidency: Models of Engagement with International Organizations. International Organisations Research Journal (IORJ), 11 (2), 113-139. DOI: 10.17323/1996-7845-2016-02-113. (In Russ.).

Larionova, M. V. (2017). G20 and BRICS: Engaging with International Organizations to Generate Growth. International Organisations Research Journal (IORJ), 12 (2) (forthcoming). (In Russ).

Larionova, M. V., Rakhmangulov, M. R., Sakharov, A. G., \& Shelepov, A. V. (2014). BRICS: Emergence of Health Agenda. International Organisations Research Journal (IORJ), 9 (4), 102-125. DOI: 10.17323/1996-7845-2016-03-99. (In Russ.).

Larionova, M. V., Rakhmangulov, M. R., \& Shelepov, A. V. (2016). Explaining G20 and BRICS Compliance. International Organisations Research Journal (IORJ), 11 (3), 99-131. (In Russ).

Larionova, M., \& Shelepov, A. (2015). Is BRICS Institutionalization Enhancing its Effectiveness. In: Rewizorski M. editor. The European Union and the BRICS: Complex Relations in the Era of Global Governance. Springer. p. 39-55.

Putnam, R., \& Bayne, N. (1987). Hanging Together. Cooperation and Conflict in the Seven-Power Summits. London: Sage Publications.

Shelepov, A. V. (2015). BRICS and International Institutions: Models of Engagement in Global Governance. International Organisations Research Journal (IORJ), 10 (4), 7-28. (In Russ.).

Received: 04.02.2017

For citations: Safonkina, E.A. (2017). Asia-Pacific Economic Cooperation (APEC): Models of Engagement with International Institutions in the Process of Regional Governance. Vestnik RUDN. International Relations, 17(1), 122-136.

\begin{abstract}
About the author: Safonkina Elizaveta Andreyevna - Researcher of the Center for International Institutions Research (CIIR), Russian Academy of National Economy and Public Administration under the President of the Russian Federation (RANEPA) (e-mail: safonkina-ea@ranepa.ru).
\end{abstract}

